that existing arrangements for training scientists, technicians and managements in scientific photography are inadequate, and that the low pay offered to scientific and medical photographers does not encourage pursuit of these occupations. Research workers have difficulty in obtaining information which would assist them in applying photographic methods, but certain advisory technical and re. search facilities could usefully be provided to assist them. Facilities for research photography are unco-ordinated in many universities; there is also lack of co-ordination between users and producers of educational film for universities, and existing distribution facilities for research films are inadequate.

The working party surveyed the demand for research films and their availability, and the use and improvement of scientific photography in research in Britain, as well as its use overseas. Recommendations were adopted propos. ing the establishment of an information service, preferably in some Government research establishment. The establishment was suggested of a central research photography unit, incorporating the information centre and financed jointly by Government and industry, the main function of which would be to conduct research on the techniques and development of scientific photography, and to encourage its use in industry and the universities. This it would do by rendering technical assistance and consultancy services where these are not readily available. Besides the establishment of a department of scientific photography in a suitable university or college of advanced technology, short advanced courses in scientific photography should be instituted in such colleges, particularly directed to the needs of scientists in industry. Central photography units should be encouraged in universities and, with the help of these units, universities should form their own libraries of 'concept film' as an aid in advanced teaching. The working party considered that the Department of Scientific and Industrial Research should be invited to compile, primarily as an aid in locating research film, a directory of users of cinematography in research in Britain, based on information already collected. The possibilities of making or compiling a film or films illustrating the techniques and applications of scientific photography should also be looked into carefully.

The recommendations relating to a university depart. ment of scientific photography, central photography units in universities and a research film library fall within the terms of reference of a Joint Committee of the University Grants Committee, the Department of Education and Science and the Scottish Education Department. It was appointed in 1963 to survey the present use of audio-visual aids in teaching and research in the pure and applied sciences in higher education. It is not expected, therefore, that these particular recommendations will be implemented beforo that Committee reports in 1965 .

\title{
OCEANOGRAPHY IN THE CARIBBEAN AND EASTERN ATLANTIC
}

\begin{abstract}
N. 2 of the first volume of the Boletin issued by the recently established Oceanographic Institute at the Universidad de Oriente, Cumana, Venezuela*, contains five papers, the high standard and choice of subjectmatter of which promise well for the future of the subject, in an area where oceanography and the scientific approach to fisheries problems have hitherto received little attention; and that little mainly offshore work during longrange cruises by research ships from the United States and other countries, with all the unavoidable lack of seasonal coverage that this implies.

The emphasis has clearly been on filling the gaps in basic knowledge of the hydrology of the region, both seasonally and into the inshore areas where no extensive observations had hitherto been made; while on the biological side correlation between organic sedimentation and the hydrology of the bay most readily accessible from the new laboratory and the revision of the systematics of a group of fishes important to the local inshore fishery, with detailed description of their osteology, will both help to provido a basis for future research on obviously desirable lines.
\end{abstract}

For these reasons it would seem that the director of the new institute deserves congratulations on his choice of studies to be encouraged, no less than tho individual researchers on the high standard of presentation of their observations. Apart from their local significance the hydrological papers contain much of interest to oceanographers generally.

In the first paper, Herman G. Gade describes oceanographic observations in the south-eastern Caribbean Sea and adjacent Atlantic waters with special reference to the influence of the Orinoco River. Two cruises carried out in August 1960 and April 1961 by the R.V. Guaiqueri give adequate coverage for the region northwards from the

* Boletin del Instituto Oceanografico, Volumen 1, Numero 2. Pp. 287-482. Suscripcion: Bs. 10 por volumen de dos numeros; Bs. 6 por numero suelto,
(Cumana, Venezuela: Universidad de Oriente, Instituto Oceanografico, 1961.) delta, with a special investigation of the shallow Gulf of Paria between Trinidad and the mainland, and "round the corner" into the Caribbean.

There was great seasonal fluctuation in the volume of the upper water of the region. In the Atlantic the depth of the transition zone varied from $100 \mathrm{~m}$ in August to $160 \mathrm{~m}$ in April. The offshore surface water changed from less than $34 \%$ to more than $36 \%$ salinity during the same period. The slope of the isopycnals indicated moderate upwelling towards the coast in both Atlantic and Caribbean regions. This was considered to be a result of strong currents parallel to the coast, and was most intense during the dry season. There were indications of a counter current below and within the transition zone in both regions. This soems analogous to the similar effect suspected (though not yet proved) to exist below the upwolling zone in the Benguela current ${ }^{1}$. Here, the maintenance of the sub-surface salinity maximum is attributed to this feature. The negative anomaly of surface temperature in the coastal upwelling zone of the Caribbean region reached as much as $5^{\circ} \mathrm{C}$ in the dry season. The ocean current entering the Caribbean through Tobago Sound appeared as a strong jet affecting conditions as far west as Curaçao.

Within the Gulf of Paria a western region of low salinity was separate from a region of more oceanic water to the east. The eastern and central waters of the Gulf appeared to be rotating clock-wise. In the north, three layers of water were distinguished: the two upper ones of Gulf water, the lower one of Caribbean origin. While the residual current flows through the Gulf from south to north, Caribbean water may at times penetrate into it at all levels under the influence of tidal currents, but chiefly below the surface layer through the Dragon's Mouth. In the appendix the strength of the anticyclonic circulation in the gulf is discussed on the basis of the deformation of the sub-surface isopycnals. In the theoretical model the water rotates as a rigid body. Applied to the observed 
data, the corresponding angular velocity was found to be $0 \cdot 17$ radians $/ \mathrm{h}$.

The fresh-water discharge from the Orinoco and other Guiana rivers is carried by the ocean current some distance offshore. To the north of Venezuela it is displaced to the north of the upwelling zone and is not found along the coast. It follows the ocean current from Tobago Sound in a west-north-west direction and flows like a river into the central southern parts of the Caribbean Sea. This system appears quite stable except perhaps in September/October when slackening of the trade wind greatly reduces the coastal upwelling.

The Amazon discharge culminates in July and is carried by the Guiana current into the Caribbean, but is sometimes separated from the Orinoco water by a band of higher salinity. The bulk of the tropical low-salinity water (greatly augmented by precipitation at sea, in addition to the effects of Amazon discharge) enters the Caribbean north of $12^{\circ} \mathrm{N}$.

Towards the end of the year the Amazon discharge is scarcely detectable in the Atlantic, and the Orinoco discharge becomes the main source of reduced salinities in the south-eastern Caribbean, its effects being limited to the south by the coastal upwelling and to the north by Atlantic water of the main Caribbean current.

In the next paper K. Kato discusses the relationships between organic sedimentation in Mochima Bay and the hydrological conditions. The sediment samples from 35 stations were collected by Dr. Roa Morales in October, and hydrological observations were made in November 1960.

The bay is a small narrow inlet on the East Coast of Venezuela opening into the Caribbean, some $8 \mathrm{~km}$ long north and south, and $2.3 \mathrm{~km}$ wide (not $23 \mathrm{~km}$ as printed). In contrast to conditions in the Gulf of Cariaco, where the prevailing easterly wind carries out the surface waters, setting up a fairly constant circulation as they are replaced by sub-surface movements, the waters of Mochima Bay, surrounded by mountains and with its opening to the north, are little influenced by winds. Here, water transport seems to be mainly due to tidal motion.

On the basis of organic carbon content, the bay was divisible into four sub-areas: (1) The entrance to Punta Garrapata, where the sediments were very poor in organic carbon, $<0.25$ per cent. (2) The narrow channel with carbon content still low, $<0.5$ per cent, but rising near shore to <1 per cent. (3) The north-eastern part of the interior, carbon content still mainly < 1 per cent. (4) The south-western head of the bay, where there was abundant accumulation of organic matter, more than 6 per cent organic carbon at some stations, with average values of 2.8 per cent. Here also the $p H$ value of the mud was appreciably lower than in the other sub-areas.

The attempt to determine possible relations between this disposition of organic sedimentation and the hydrobiological régime involved hydrological and chemical observations carried out at five stations, one to give the conditions in the Caribbean coastal water outside the bay, and one in each of the four sub-areas. Temperature, density, salinity, dissolved oxygen, nitrate, nitrite, phosphate and silicate were determined, following standard methods established by the Japanese Society of Oceanography. The results are described in detail with good graphic presentation.

There were temperatures of $24^{\circ}-25^{\circ} \mathrm{C}$ in the upper $5 \mathrm{~m}$ of the bay water, where the stability was very high. Subsurface water from the outer Caribbean penetrated below the well-defined discontinuity layer at the flood tide and reached the bottom of the bay about the seaward boundary of the innermost sub-area. Here it came in contact with the interior bay water and this border (or slant plane) extended obliquely towards the surface seawards, nearing the surface in the narrow channel. It is held that appreciable turbulence may develop along the border where there is said to be much biological activity. A most vigorous growth of phytoplankton is said to occur here, but turbulence seems sufficient to prevent oxygen depletion, with comparatively rapid re-cycling of organic constituents and hence comparatively high $p \mathrm{H}$ values in the bottom muds.

The more stagnant water at the head of the bay seems isolated from the inflowing water. It contained abundant nutrients and a vigorous phytoplankton devalopment in the surface layer, thought to be distinct from the dense population found in the channel area, with super-saturation of oxygen. The bottom water in this interior sub-area, however, showed oxygen depletion, and here there was an abundant accumulation of organic matter, as much as $1 \cdot 3-6 \cdot 5$ per cent in organic carbon content.

A direct plankton investigation comparing the populations in the two distinct areas of high productivity should not be too difficult, and would go far towards confirming the general picture. This seems exceptionally clear and well presented. No doubt complexities would obtrude if a whole seasonal cycle were investigated, but the prime consideration of the bottom deposits, which might be termed a semi-conservative element, seems to have ensured that the summation effect is fairly represented; that the investigator has, in fact, allowed Nature to do some of his integration for him.

The third paper, by Herman G. Gade, describes the hydrographic observations during January-May 1961. carried out in continuation of his earlier work in the Gulf of Cariaco, and discusses the circulation and water exchange conditions they reveal. The Gulf of Cariaco is a much larger inlet than Mochima Bay, lying south of the Peninsula de Praya with its long axis east and west, and opening to the west. Thus the horizontal shear set up by the prevailing dry-season winds becomes the prime factor in maintaining the circulation within the Gulf. The inflow during these months is derived from the salinity maximum layer and below. Upwelling takes place fairly regularly within the Gulf, but is normally limited to water above $50 \mathrm{~m}$. Below this the water exchange is slow except for a prriod during the dry season when the external water is heavier and the deeper layers participate in the exchange. Outflow is general above $25 \mathrm{~m}$, and there is a compensation current below that depth. The repeated observations showed that the maximum period of deep upwelling fell earlier than during the 1960 season. This was thought to be connected with variations in the moro general upwelling along the northerm coast of Venezuela and, consequently, in the thickness of the upper water layer.

There seemed to be an almost permanent circulation of the upper layers inside the Gulf maintained by the wind shear, and this was verified by many drift measurements with current crosses, while the vertical circulation was studied directly by observations with Ekman current meters, in addition to the eections showing isohalines, isopycnals and oxygen isopleths, to obtain what is believed to be a typical profile of the vertical current distribution near the mouth of the Gulf.

The total flushing period of the Gulf was estimated to be 20 days, but in periods when the exchange is limited to higher levels the period would be shorter. The upper layers are much warmer than can be accounted for by the incoming radiation alone, and their salinity also is sometimes higher than the surface evaporation alone could account for. It is suggested that this is due to occasional reversal of the circulation during periods of calm or westerly winds, when the upwelling process must be slowed or stopped. This would be a direct analogy with the largerscale anomalies that affect the normal régime of upwelling off the western coasts of the continents at times when the wind conditions become atypical'

A most dotailed description of the osteological characters of eight species of Pomadasyidae is presented by Francis Mago Leccia in the fourth paper. The work was carried out with the definite objective of providing a sound systematic basis for future bionomic research on this family of 
Perciforme fishes, known locally as corocoros. To further that end the paper is well and copiously illustrated, and convenient tabulations of the characters deemed taxonomically significant are provided. The importance of the group to the local fishery is shown by the fact, mentioned in the introduction, that already by 1959 more than 200 tons of them were being marketed annually.

The illustrations bring out clearly one point, not specifically dealt with by the author, but which is still likely to prove important in any future population studies on the group: whereas the otoliths look unpromising material for age-determinations, some of the other bones provide clear indications of growth zones, notably the supraoccipital crest of Haemulon plumieri and several of the opercular bones of Orthopristis ruber. Apart from their value in dealing with some fresh-water fishes, exemplified by Le Cren's ${ }^{2}$ investigations of perch in Lake Windermere, the use of bones other than otoliths has been found useful in studying the growth of several very diverse species of marine fishes (see Menon ${ }^{3,4}$ and Chang ${ }^{5}$ ).

This number of the Boletin is concluded by a short. systematic paper by R. A. Curra of the new Institute, and P. de Miranda Ribeiro of the National Museum of Brazil (a pioneer in several lines of aquatic biology in Latin America). This seeks to establish the taxonomic position: of a rare species of gymnotid fish first deseribed by the latter in 1920, Urumara rondoni Miranda Ribeiro. To further this end, the main diagnostic characters of the three genera at present included in the family Rhamphichthyidae are illustrated and a formal key is provided. T. J. HART

${ }^{1}$ Hart, T. J., and Curries, R. I., "The Benguela Current", Discovery Rep., 31. $123(1960)$.

" Le Cren, E. D., J. Anim. Ecol., 16, 188 (1947).

3 Menon, N. D., J. Mar. Biol. Assoc. 29, No. 1, 185 (1950).

4 Menon, N. D., J. Cons. Internat. Explor. Mer., 16, 311 (1950).

5 Hsiao-Wei Chang, J. Mar. Biol. A ssoc., 30, No. 2, 281 (1951).

\title{
EQUATORIAL UNDERCURRENT IN THE WESTERN INDIAN OCEAN
}

\author{
By Dr. J. C. SWALLOW, \\ R.R.S. Discovery, c/o General Post Office, London
}

$\mathrm{F}^{\mathrm{o}}$ OUR times during March-June this year, the equatorial undercurrent has been observed by the R.R.S. Discovery in the course of its participation in the International Indian Ocean Expedition. We have found much higher speeds than those reported by Knauss and Taft ${ }^{1}$ in the same season of the previous year, and a brief preliminary account may be of interest although not all the results have yet been processed.

Knauss and Taft found only a weak undercurrent in the western Indian Ocean, with maximum speeds generally less than $50 \mathrm{~cm} / \mathrm{sec}$ and sometimes scarcely any significant eastward flow at all. In contrast, two of our sections showed speeds exceeding $120 \mathrm{~cm} / \mathrm{sec}$, comparable with those found in the Pacific undercurrent, and some subsurface eastward movement was always found.

On the first three crossings of the equator, a buoy was anchored at each of the stations shown (Figs. 1-3). Water movement relative to the ship was measured with direct. reading current-meters ${ }^{2}$ and the ship's drift was determined by radar relative to the anchored buoy. Drogues were also used for measuring the near-surface current.

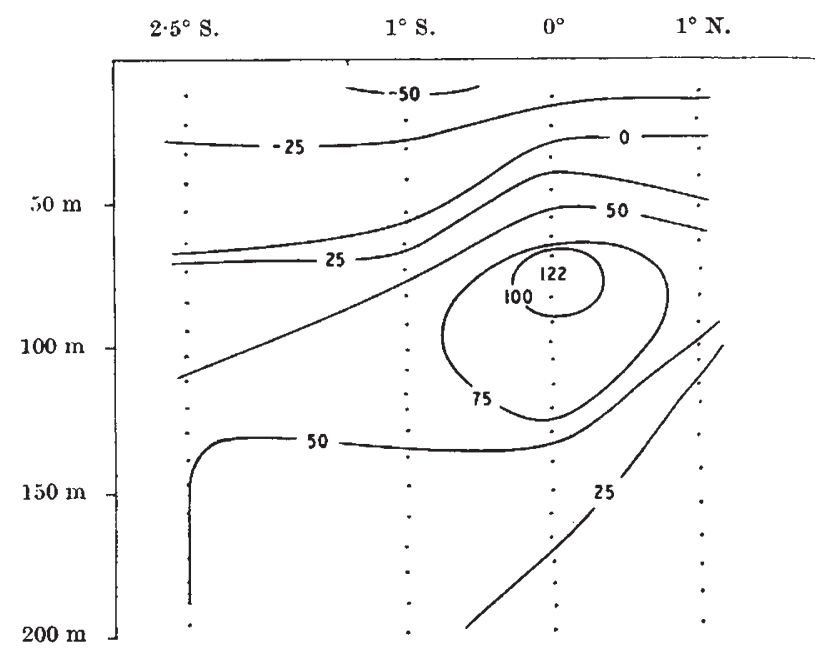

Fig. 1. Section 1,58 E. March 18-23, 1964. Eastward component of velocity in $\mathrm{cm} / \mathrm{sec}$
Section $1,58^{\circ}$ E., March 18-23, 1964. The undercurrent was centred on the equator, with a maximum eastward speed of $122 \mathrm{~cm} / \mathrm{sec}$ at $75 \mathrm{~m}$ depth, in the thermocline. The meridional component there was $28 \mathrm{~cm} / \mathrm{sec}$ southward. The eastward speed falls to about half-value at $1^{\circ} \mathrm{N}$. and $1^{\circ} \mathrm{S}$. and meridional flow in the undercurrent was relatively weak at all stations. Spreading of the thermocline was only slight, the separation of the $15^{\circ} \mathrm{C}$ and $25^{\circ} \mathrm{C}$ isotherms being $105 \mathrm{~m}$ at the equator, and $80-95 \mathrm{~m}$ at $2^{\circ} \mathrm{S}$. and $2^{\circ} \mathrm{N}$. The water in the undercurrent had a high salinity, the maximum values decreasing from north to south. At the equator the maximum was 35.55 parts per thousand at $100 \mathrm{~m}$, slightly deeper than the high-speed core. Surface currents were north-west. $30-60 \mathrm{~cm} / \mathrm{sec}$, at $1^{\circ} \mathrm{N}$., the equator and $1^{\circ} \mathrm{S}$., and southwest, $50 \mathrm{~cm} / \mathrm{sec}$, at $2 \frac{1}{2}^{\circ} \mathrm{S}$.

This section would be very similar to typical Pacific sections but for the asymmetry due to the deeper eastward flow at the southerm end of the section.

Evidence in support of the persistence in time, and continuity with longitude, of the undercurrent comes

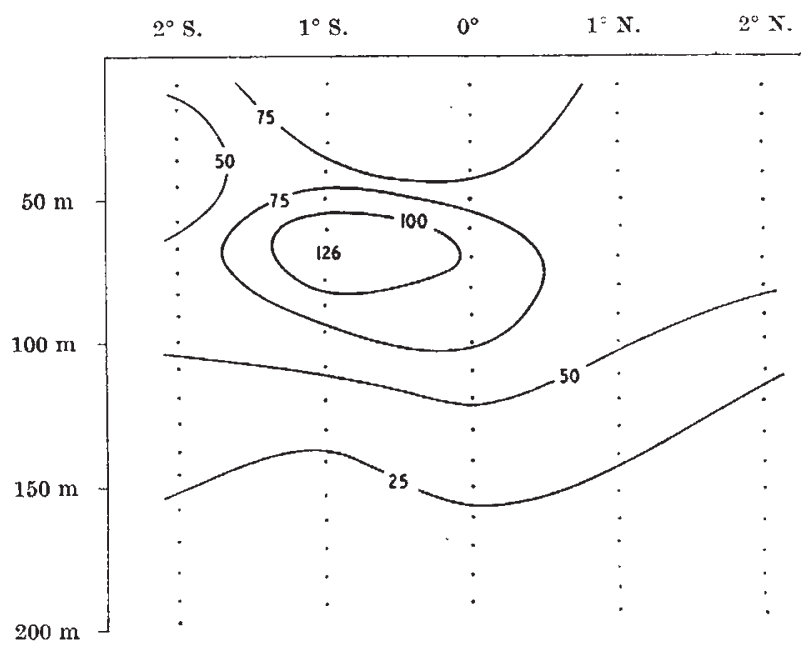

Fig. 2. Section 2, $67^{\circ} 30^{\prime}$ E. April 26-May 1, 1964. Fastward component of velocity in $\mathrm{cm} / \mathrm{sec}$ 